POLSKA AKADEMIA NAUK Z ZAKEAD BADANIA SSAKOW

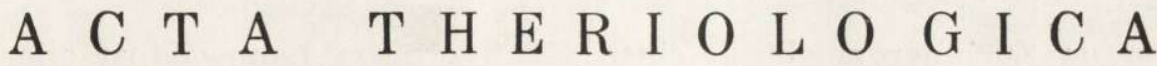

VOL. V, 5 .

BIAŁOWIEŻA

10.VI.1961

Julian S C I B O R

\section{Die Entwicklung der Wisentzucht im Urwald von Białowieża}

\author{
Rozwój hodowli żubrów w Puszczy Białowieskiej \\ Bisoniana III \\ [Mit 3 Tabellen]
}

Die Kopfanzahl der Wisente im Polnischen Areal des Białowieżaer Urwaldes in Freiheit und in Gehegen gestaltete sich in den letzten zwei Jahren so wie dies auf Tabelle 1. angegeben ist. Die Anordnung der Tabelle ist derartig, dass sie das Orientieren inbetreff der Alterszusammensetzung und des zahlenmässigen Geschlechtsverhältnisses ermöglicht.

Der Zuwachs an Jungvieh betrug im Jahre 1960 - 13 Kälber. Angenommen, dass das eigentliche Geschlechtsverhältnis in der Herde sich wie $10^{i}: 4$ q verhalten soll, so befinden sich in der Zuchtgruppe 18 überzählige Bullen.

Änderungen in der Białowieżaer Herde gestalteten sich im Jahre 1960 so, wie dies auf Tabelle 2 angegeben ist.

Die Anzahl Białowieżaer Wisente ist in drei Gruppen eingeteilt:

1. Die Zuchtherde, die sich in Gehegen in den sogenannten „Reservaten" befindet. Dort haben wir 4 Reproduktionsgruppen, die aus 4 Bullen und 14 Kühen, weiter 12 überzähligen Bullen und 8 noch geschlechtsunreifen, jungen Färsen bestehen. Insgesamt also 38 Stück Wisente. 
Die Zuchtherde lebt in einer $205 \mathrm{~h}$ grossen Laubwaldparzelle, die mit einem $2 \mathrm{~m}$ hohen, dichten Zaun umgeben ist. Das Ganze ist in 10 Gehege mit einer Fläche von 4 bis $80 \mathrm{~h}$ eingeteilt. Als minimale Fläche für einen Wisent vereinbarte man $5 \mathrm{~h}$. Im Jahre 1956- 57 rodete man in jedem Gehege einen Teil des Areales aus und besäte ihn mit Gras. Auf diese Weise erhielt man im ganzen ca $30 \mathrm{~h}$ guter Weide für die Wisente.

Tabelle 1.

Kopfanzahl der Wisente im polnischen Teil des Białowieżaer Urwaldes am 1. I. 1961.

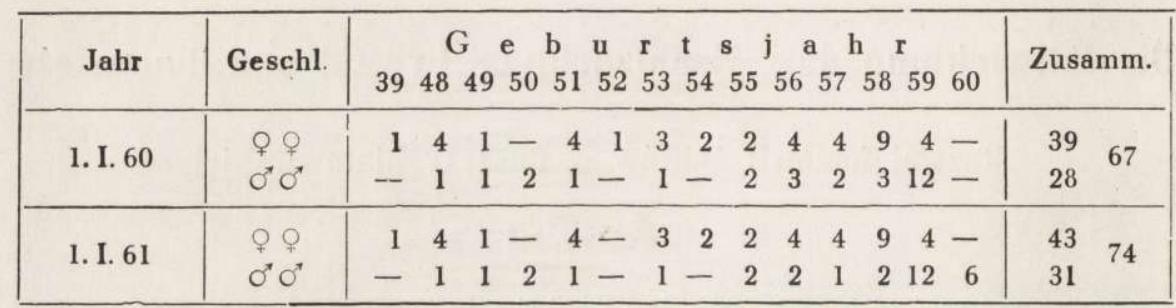

Tabelle 2.

Änderungen in der Wisentherde in Białowieża im Jahre 1960.

\begin{tabular}{|c|c|c|c|c|c|c|}
\hline \multirow[b]{2}{*}{ Geschl. } & \multirow{2}{*}{$\begin{array}{c}\text { Bestand } \\
\text { am } \\
\text { 1.I } 1960\end{array}$} & \multirow{2}{*}{$\begin{array}{c}\text { Zuwachs } \\
\text { durch } \\
\text { Geburt }\end{array}$} & \multicolumn{3}{|c|}{ 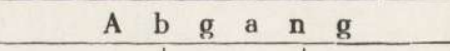 } & \multirow{2}{*}{$\begin{array}{c}\text { Bestand } \\
\text { am } \\
\text { 1.I.1961 }\end{array}$} \\
\hline & & & $\begin{array}{l}\text { zugrunde } \\
\text { gegangen }\end{array}$ & $\begin{array}{l}\text { ins } \\
\mathrm{ZOU}\end{array}$ & $\begin{array}{c}\text { ins } \\
\text { Ausland }\end{array}$ & \\
\hline 우 우 & 39 & 5 & - & 1 & - & 43 \\
\hline $0^{\circ} 0^{\circ}$ & 28 & 8 & 2 & 1 & 2 & 31 \\
\hline Zusamm. & 67 & 13 & 2 & 2 & 2 & 74 \\
\hline
\end{tabular}

Jedes von den 10 Gehegen besitzt wirtschaftliche Vorrichtungen wie: Tränkanlage, Futtertrog, Offenstall und Kälberboxen zum Füttern.

2. Die in völliger Freiheit lebende Herde (Ścibor, 1960) ist jetzt bis zu 34 Stück angewachsen. Die erhaltenen Untersuchungsergebnisse sind sehr günstig und weiterhin sehr anregend. Die Kondition der in Freiheit lebenden Tiere ist ausgezeichnet. Wie früh- 
er teilt sich die Herde während der Brunstperiode in drei Gruppen und sie wandert in einem Radius von $10 \mathrm{~km}$ um die Winterstände herum.

3. Die Untersuchungsgruppe, die dem Institut für Säugetierforschung überwiesen wurde, besteht aus 3 Stück, 1 Bullen und 2 Kühen. Sie befindet sich im Versuchsreservat der Polnischen Akademie der Wissenschaften.

Alle sich im Gelände von Białowieża befindenden Wisente stammen von Vorfahren ab, die ehemals den Urwald von Białowieża bewohnt haben.

Bei der Restitution der Herde im Jahre 1929 wandte man anfänglich die Inzucht an. Dies löste keinen degenerierenden Einfluss auf die Kopfanzahl aus. Das Jungvieh entwickelt sich gut, die Geburten verlaufen normal und der Gesundheitszustand erregt keine Sorgen und keinen Vorbehalt.

Auf 117 Kalbungen seit dem Jahre 1944 zog man 102 Wisente gross d. i. $87 \%$. Der Anwuchs der Herde beträgt durchschnittlich $24 \%$. Von der Gesamtheit der sich zur Vermehrung eignenden Kühe kalbt $74 \%$. Angaben über Vermehrung der Wisente sind eingehend von Jaczewski (1954) bearbeitet worden.

Von den interessanteren Beobachtungen, die in der Zuchtherde durchgeführt wurden, ist zu erwähnen, das zweimal die zweite Deckung von schon seit 2 Monaten trächtigen Wisentkühen festgestellt wurde. Die Kälber wurden normal geboren (im eigentlichen Termin für die erste Deckung) und sie entwickeln sich gut.

Wenn es sich um die in der Freiheit lebende Herde handelt, wird sie in der Winterperiode in drei Futterkrippen mit Heu nachgefüttert. Durchschnittlich gibt man täglich $8 \mathrm{~kg}$ Heu für jedes Stück vor. Die Lebenserhaltungskosten betragen für einen in völliger Freiheit lebenden Wisent $25 \%$ derjenigen im Gehege.

Die in Freihet lebende Herde wechselt ihre Lagerplätze auf eine sehr charakteristische Weise. Einen gewissen Weideplatz benutzt sie $1-3$ Tage und auf denselben Platz kommt sie nicht vor zwei Wochen wieder, d. i. dann, wenn das Gras und junge Schösslinge von Bäumen oder Sträuchern wieder nachwachsen.

Es ist beobachtet worden, dass Wisente nur die oberen Abschnitte der Grashalme ausnutzen. Ihre Weideplätze leiden mehr vom Zertreten als vom Abweiden.

Wenn es sich um Bäume und Straucher handelt, dann schälen Wisente am gernsten Eschen, Weiden und Espen, in weiterer Folge 
Linden und anderes Laubholz. Birken rühren sie fast garnicht an. Nadelbäume entblössen sie nur sehr selten von der Rinde. Während der Periode des Eichelfallens nähren sich die Wisente fast ausschliesslich mit ihnen, und hören fast gänzlich auf, Bäume und Sträucher zu entrinden.

Tabelle 3.

Allgemeine Wisentanzahl in Polen am 31. XII. 1960.

\begin{tabular}{|c|c|c|c|c|c|c|c|c|}
\hline \multirow[b]{2}{*}{ Reservat } & \multirow[b]{2}{*}{ Zusamm. } & \multicolumn{3}{|c|}{ Zuchtherde } & \multirow{2}{*}{\multicolumn{2}{|c|}{$\begin{array}{l}\text { Jungvieh } \\
0^{+} 0^{+}+?\end{array}$}} & \multirow{2}{*}{$\begin{array}{l}\text { Kälber } \\
\sigma^{*} 0^{*}\end{array}$} & \multirow{2}{*}{$\begin{array}{r}1960 \\
q ?\end{array}$} \\
\hline & & Bullen & Kühe & $\begin{array}{c}\text { trächtige } \\
\text { Färsen }\end{array}$ & & & & \\
\hline Herde „PO“ & & & & & & & & \\
\hline Białowieża-Reservat & 40 & 6 & 12 & 2 & 7 & 7 & 4 & 2 \\
\hline Bialowieża-Urwald & 34 & 5 & 9 & 2 & 7 & 6 & 2 & 3 \\
\hline Zusammen & 74 & 11 & 21 & 4 & 14 & 13 & 6 & 5 \\
\hline Herde „PU“ & & & & & & & & \\
\hline Niepolomice & 25 & 1 & 6 & 2 & 8 & 3 & 2 & 3 \\
\hline Pszczyna & 26 & 2 & 8 & 1 & 7 & 2 & 1 & 5 \\
\hline Borki & 11 & 1 & 4 & - & 4 & 1 & - & 1 \\
\hline Smardzewice & 9 & - & - & - & 9 & - & - & - \\
\hline Zusammen & 71 & 4 & 18 & 3 & 28 & 6 & 3 & 9 \\
\hline ZOO & 10 & 8 & 2 & - & - & - & - & - \\
\hline Zusammen & 155 & 23 & 41 & 7 & 42 & 19 & 9 & 14 \\
\hline
\end{tabular}

Im frühen Frühjahr weiden Wisente fast ausschliesslich im Erlen-Eschen-Tannenwald an den Ufern von Bächen und fressen, das sich am frühesten entwickelnde Riedgras ab.

Die im Jungwald durch Wisente verursachten Schäden sind beträchtlich, jedoch verhältnismässig kleiner als diejenigen, die durch Schalenwild verübt werden. Es scheint, dass bei einer Besetzung ein Wisent auf $250 \mathrm{~h}$ diese Tiere keinen wesentlichen Schaden im Forstbestand ausrichten werden.

Allgemeine Angaben über die Anzahl der Wisente in Polen enthält Tabelle 3. 


\section{SCHRIFTTUM}

1. J a z zewski, Z., 1958: Reproduction of the European bison, Bison bonasus (L.). Acta Theriol., 1, 9: 333-376. Warszawa.

2. Scibor, J., 1960: Beobachtungen über die in der Freiheit lebenden Wisente im Urwald von Białowieża. Ib., 3, 14: 312-314. Białowieża.

Polnische Akademie der Wissenschaften, Institut für Säugetierforschung in Białowieża.

\section{STRESZCZENIE}

Autor podaje aktualny stan hodowli żubrów w Białowieży. Ogółem w Białowieży znajduje się 75 żubrów (Tabela 1). W ciągu roku 1960 urodziło się 13 cieląt, ubyło zaś 5 (w tym 2 padły, 1 - przekazany do Zoo, 2- przekazane za granicę). (Tabela 2). Żubry bytujące w Białowieży dzielą się na trzy grupy: 1. stado hodowane w 2 rezerwatach zamkniętych -38 sztuk, 2. stado bytujące na wolności - 34 sztuki, oraz 3 . grupa doświadczalna Zakładu Badania Ssaków PAN - 3 sztuki.

Naturalny przyrost żubrów w Białowieży wynosi $24 \%$. Odchowuje się (średnio za okres $1944-1960$ ) 87\% urodzonych cieląt.

Stan lijezebny żubrów w Polsce na dzień 31. XII. 1960 wyraża się liczbą 155 sztuk. Rozmieszczenie w rezerwatach i ogrodach zoologicznych ilustruje tabela 3 . 
BIBLIOTEKA

Instytutu Biologii Ssaków

Polskiej Akademii Nauk

NrCz. 40.2 